\title{
Cerebellar syndrome following neuroleptic induced heat stroke
}

\author{
DAVID LEFKOWITZ, C STEPHEN FORD, CHARLES RICH,${ }^{*}$ JOSÉ BILLER ${ }^{\dagger}$ \\ LAWRENCE C MCHENRY JR \\ From the Department of Neurology, Bowman Gray School of Medicine of Wake Forest University, \\ Winston-Salem, North Carolina, USA
}

SUMMARY We report a patient in whom extreme hyperthermia, rhabdomyolysis, acute renal failure and a residual pancerebellar syndrome occurred while taking a combination of perphenazine and amitriptyline. We postulate that impaired thermoregulation due to psychotropic drugs was responsible for the development of heat stroke and that the cerebellar syndrome resulted directly from the elevated temperature.

Residual neurological deficits after recovery from hyperthermia, particularly heat stroke, are well known $^{1}$ and probably result directly from elevated body temperature. ${ }^{2}$ Impaired thermoregulation in patients taking neuroleptic drugs may lead to hyperthermia. We present a case in which hyperthermia with rhabdomyolysis, renal failure, and a persistent cerebellar syndrome developed during therapy with perphenazine and amitriptyline.

\section{Case report}

A 50-year-old woman was found in her home one hour after having collapsed. When discovered, she was alert, sweating, and unable to walk without assistance. She repeatedly became sweaty and subsequently collapsed again without losing consciousness, but was confused and was admitted to hospital. She had been taking a perphenazine and amitriptyline combination 4-25 and diazepam $10 \mathrm{mg}$ each four times a day for seven years. On physical examination rectal temperature was $42 \cdot 5^{\circ} \mathrm{C}$ and

*Present address: Department of Internal Medicine, Grady Memorial Hospital, Atlanta, Georgia 30304, USA.

†Present address: Department of Neurology, Loyola University Medical Center, 2160 South First Avenue, Maywood, Illinois 60153, USA.

Address for reprint requests: Dr David Lefkowitz, Department of Neurology, Bowman Gray School of Medicine of Wake Forest University, Winston-Salem, North Carolina 27103, USA.

Received 2 July 1982 and in revised form 14 October 1982 Accepted 20 October 1982 blood pressure was $100 / 80 \mathrm{~mm} \mathrm{Hg}$. She was drowsy with eye deviation downward and to the left. Initial laboratory evaluation revealed a serum glucose of $0.6 \mathrm{~g} / \mathrm{l}$ and abnormal liver function tests. Chest radiographs showed interstitial oedema. Computed cranial tomography (CT) and spinal fluid examination were normal. The patient required ventilatory support and was treated with aspirin suppositories and a cooling blanket. Progressive deterioration of renal function necessitated dialysis.

After initial improvement in mentation, she deteriorated unexpectedly and was transferred to North Carolina Baptist Hospital. Examination on admission revealed diffuse ecchymoses, bilateral basal rales and hepatomegaly. She was unresponsive to pain and hyporeflexic with flexor plantar responses. The BUN was $0.92 \mathrm{~g} / \mathrm{l}$, creatinine 0.105 $\mathrm{g} / \mathrm{l}$, potassium $6 \cdot 3$ moles/l, CK $362 \mathrm{U} / \mathrm{l}(\mathrm{n} / 50-160 \mathrm{U} / \mathrm{l})$, LDH $816 \mathrm{U} / \mathrm{l}$, and aldolase $29 \mathrm{U} / \mathrm{l}$ (nl 7-24 U/l). Serum myoglobin was $1687 \mu \mathrm{g} / \mathrm{l}(\mathrm{nl} 6-85 \mu \mathrm{g} / \mathrm{l})$. Haematocrit was $32 \%$ with normal red cell indices. Prothrombin and partial thromboplastin times were normal. Fibrin degradation products were present in a concentration between 0.32 and $0.64 \mathrm{~g} / \mathrm{l}$. Repeat lumbar puncture was normal. CT showed cerebral atrophy.

With supportive care and dialysis, mental status and renal function improved. As the patient improved, her neurological deficit became apparent. There was ataxic, dysarthric speech and marked ocular dysmetria. Mild, generalised weakness was more marked proximally. There was truncal ataxia, hypotonia, and marked dysmetria of all four extremities. Sensation was normal. Muscle stretch reflexes were symmetrically brisk. Plantar responses were flexor. CT, CSF protein electrophoresis, plasma, zinc, urine for heavy metals, serum copper and ceruloplasmin levels were normal. Peripheral nerve conduction velocities, EMG and brainstem auditory responses were normal. 


\section{Discussion}

This patient developed extreme hyperthermia, rhabdomyolysis, acute renal failure and a residual cerebellar syndrome while taking perphenazine and amitriptyline. We speculate that hyperthermic cerebellar damage resulted from heat stroke related to psychotropic medications. To our knowledge, a permanent cerebellar syndrome following neurolepticinduced heat stroke has not been previously described.

Heat stroke occurs when an individual's ability to dissipate heat is overwhelmed by heat absorbed from the environment or produced by the body. Severe neurological symptoms such as coma and delirium are associated with multiple organ system dysfunction and elevated body temperatures, usually above $41^{\circ} \mathrm{C}$. The onset is abrupt in $71 \%$ of cases, but nonspecific prodromal symptoms including nausea, dizziness, confusion, restlessness, drowsiness, and exertional "faints" may occur. ${ }^{23}$ Other neurological manifestations of acute heat stroke include hallucinations, seizures, oculogyric crises, tremor, dystonia, pupillary abnormalities, decerebrate rigidity and hemiplegia. ${ }^{34}$ Although these findings are generally reversible, neurological abnormalities may be permanent. A cerebellar syndrome is the most common persistent abnormality. ${ }^{15-7}$ Residual pyramidal signs and mental status changes commonly have been reported. ${ }^{5}$ Dysarthria, dysphagia, hemiplegia and lower motor neuron findings may also persist after heat stroke. ${ }^{138}$ Patients with heat stroke are generally hypotensive, tachypnoeic and tachycardic on presentation. Haemorrhagic complications are common. Heat-induced endothelial injury may precipitate disseminated intravascular coagulation. ${ }^{4}$ Renal failure can result from direct thermal injury to the kidneys, hypoperfusion or myoglobinuria. Although classic descriptions of heat stroke stress the lack of sweating, patients often continue to sweat profusely. When present, anhidrosis may be due to direct thermal injury or exhaustion of sweat glands. ${ }^{9}$

Factors predisposing to the development of heat stroke include advanced age, obesity, cardiovascular disease, lack of acclimatisation to heat and poor physical conditioning. ${ }^{3}$ Alcohol and certain drugs, notably antipsychotics, may also increase the risk. Neuroleptics all have varying degrees of anticholinergic and anti-alpha-adrenergic effects. Both impair heat dissipation; anticholinergic properties decrease sweating and alpha-adrenergic blockade causes vasodilation, which may enhance heat absorption from the environment. ${ }^{10}$ Use of high potency antipsychotics such as haloperidol and fluphenazine, which have lower peripheral alphaadrenergic and cholinergic blocking activity, may lessen this problem. ${ }^{10}$ Concurrent administration of anticholinergic agents or tricyclic antidepressants, which also have anticholinergic properties, may further increase the risk to heat exposed individuals.

Antipsychotic induced heat stroke must be differentiated from the neuroleptic malignant syndrome, the cardinal features of which are hyperthermia, autonomic dysfunction, and extrapyramidal rigidity. Generally, the clinical picture develops over one to two days and follows shortly after initiation of antipsychotic therapy or dosage adjustment."11 Extrapyramidal symptoms such as tremor, bradykinesis, and rigidity predominate. Altered mental status varies from alert mutism to coma. Autonomic manifestations include pallor, ${ }^{12}$ hyperhidrosis, ${ }^{11}$ hypotension $^{13}$ or hypertension, ${ }^{14-16}$ dysuria, sialorrhoea and tachycardia. ${ }^{11}{ }^{17}$ Leukocytosis, rhabdomyolysis, renal and hepatic failure may all occur. ${ }^{11} 13$ Hyperthermia in this syndrome probably results from dopamine receptor blockade simultaneously in the basal ganglia (leading to rigidity and thermogenesis) and in the hypothalamus (impairing heat dissipation and autonomic function). ${ }^{12} \mathrm{~A}$ recent report incriminating alpha-methyltyrosine and tetrabenazine as a cause of the neuroleptic malignant syndrome suggests that dopamine depletion may play a similar role. ${ }^{18}$ There is evidence, however, that in addition to its other pharmacologic properties, tetrabenazine may be a dopamine receptor antagonist. ${ }^{19}$ Probably any dopamine blocker may cause this syndrome, but most cases have occurred with haloperidol and fluphenazine. ${ }^{17}$ The risk with lower potency antipsychotics may increase when they are given in combination. ${ }^{11}$ High antipsychotic doses are not necessary. Dehydration, exhaustion ${ }^{11}$ or preexisting organic brain disease ${ }^{17}$ appear to increase risk. An identical clinical picture, known as Stauder's lethal catatonia, has been described in untreated manic and catatonic patients. ${ }^{20}$ Differentiation from the drug induced syndrome hinges on the persistence of psychosis. ${ }^{21}$

Non-neuroleptic drugs which may cause hyperthermia include amphetamines, ${ }^{22}$ glutethimide, ${ }^{23}$ LSD,$^{24}$ phencyclidine, ${ }^{25}$ and the combination of tricyclic antidepressants and monoamine oxidase inhibitors. ${ }^{26}$ Hyperthermia and permanent neurological deficits, mostly cerebellar, may occur with lithium alone ${ }^{27}$ or combined with haloperidol. ${ }^{28}$ Other hyperthermic states including malignant hyperthermia, thyrotoxic crises, Luft's disease, and neurogenic hyperthermia can be excluded on clinical and paraclinical grounds.

Thermal injury to mammalian tissues begins at temperatures of $42^{\circ} \mathrm{C}$. Extreme heat liquifies membrane lipids, denatures enzymes, uncouples oxidative phosphorylation and alters molecular 
binding. ${ }^{32}$ The cerebellum is the part of the nervous system most susceptible to hyperthermia, followed by cerebral cortex, brainstem, and spinal cord. ${ }^{2}$ Purkinje cell loss occurs within 24 hours of heat stroke. ${ }^{2}$ Malamud asserts that the extent of neuronal degeneration in heat stroke correlates better with the degree and duration of hyperthermia than with hypoxia. Studies in passively heated animals indicate that neither lactic acidosis nor hypoxia limits the degree of hyperthermia tolerated by the central nervous system. ${ }^{3}$

\section{References}

1 Mehta AC, Baker RN. Persistent neurologic deficits in heat stroke. Neurology (Minneap) 1970;20:336-40.

2 Malamud, N, Haymaker W, Custer RP. Heatstroke, a clinico pathologic study of 125 fatal cases. Milit Surg 1946;99:397-449.

3 Shibolet S, Lancaster MC, Danon Y. Heat stroke; a review. Aviat Space Environ Med 1976;47:280-301.

${ }^{4}$ Clowes GHA Jr, O' Donnell TF Jr. Heat stroke. N Engl J Med 1974;291:564-7.

5 Weisenberg TH. Nervous symptoms following sunstroke. JAMA 1972;58:2015.

6 Freeman W, Dumoff S. Cerebellar syndrome following heat stroke. Arch Neurol Psych 1944;51:67-72.

7 Silverman JJ, Wilson JE. An unusual complication following thyroidectomy; heatstroke with permanent cerebellar changes. Ann Int Med 1950;33:1036-41.

8 Wakefield E, Hall WW. Heat injuries-a preparatory study for experimental heat stroke. JAMA 1927; 89:92-5.

9 Knochel JP. Environmental heat illness; an eclectic review. Arch Int Med 1974;133:841-64.

10 Mann SC, Boger WP. Psychotropic drugs, summer heat and humidity, and hyperpyrexia; a danger revisited. Am J Psychiatr 1978;135:1097-100.

11 Itoh H, Ohtsuka N, Ogita K, Yagi G, Miura S, Koga Y. Malignant neuroleptic syndrome-its present status in Japan. Folia Psychiatr Neurol Jap 1977;31(4):565-76.

12 Henderson VW, Wooten GF. Neuroleptic malignant syndrome; a pathogenetic role for dopamine receptor blockade. Neurology (NY) 1981;31:132-7.

13 Greenblatt DJ, Gross PL, Harris J, Shader RI, Ciraulo DA. Fatal hyperthermia following haloperidol therapy of sedative-hypnotic withdrawal. J Clin Psychiatr 1978; 39:673-5.

14 McCallister RG. Fever, tachycardia and hypertension with acute catatonic schizophrenia. Arch Int Med 1978; 138: 1154-6.

15 Geller B, Greydanus DE. Haloperidol-induced comatose state with hyperthermia and rigidity in adolescence; 2 case reports with a literature review. J Clin Psychiatr 1979;40:102-3.

16 Meltzer HV. Rigidity hyperpyrexia and coma following fluphenazine. Psychopharmacologia (Berl) 1973; 29:337-46.

${ }^{17}$ Caroff SN. The neuroleptic malignant syndrome. J Clin Psychiatr 1980;41:79-83.

18 Burke RE, Fahn S, Mayeaux R, Weinberg H, Louis K, Willner JH. Neuroleptic malignant syndrome caused by dopamine depleting drugs in a patient with Huntington disease. Neurology (NY) 1981;31:1022-6.

19 Login IS, Cronin MJ, MacLeod RM. Neuroleptic malignant syndrome caused by dopamine depleting drugs (Letter). Neurology (NY) 1982;32:218-9.

20 Powers P, Douglass TS, Waziri R. Hyperpyrexia in catatonic states. Dis Nerv Syst 1976;37:359-61.

21 Wienberger DR, Kelly MJ. Catatonia and malignant syndrome; a possible complication of neuroleptic administration. J Nerv Ment Dis 1977;165:263-8.

22 Ginsberg MD, Hertzman M, Schmidt-Nowara WW. Amphetamine intoxication with coagulopathy, hyperthermia and reversible renal failure. Ann Int Med 1970;73:81-5.

23 Zivin L, Shalowitz M. Acute toxic reaction to prolonged glutethimide administration. New Eng J Med 1962; 266:496-8.

24 Klock JC, Boerner U, Becker CE. Coma, hyperthermia and bleeding with massive LSD overdose; a report of 8 cases. Clin Toxicol 1975;8:191-203.

25 Rappolt RT, Gay GR, Farris RD. Emergency management of acute phencyclidine intoxication. J Am Coll Emerg Phys 1979;8:68-76.

26 Ponto LB, Perry PJ, Liskow BI, Seaba HH. Drug therapy reviews; tricyclic antidepressant and monoamine oxidase inhibitor combination therapy. Am J Hosp Pharm 1977;34:954-61.

27 Juul-Jensen P, Schou M. Permanent brain damage after lithium intoxication. Br Med J 1973;4:673 (Letter).

28 Cohen WJ, Cohen NJ. Lithium carbonate, haloperidol, and irreversible brain damage. JAMA 1974;230:12837.

29 Gottschalk PG, Thomas JE, Heat stroke. Mayo Clin Proc 1966;41:470-82. 